\title{
A RECENT UPDATE: ANTIMICROBIAL AGENTS CONTAINING PYRAZOLE NUCLEUS
}

\section{BAYU ARDIANSAH*}

Department of Chemistry, FMIPA, Universitas Indonesia, Depok 16424, Indonesia. Email: bayu.ardiansah@sci.ui.ac.id

Received: 30 August 2018, Revised and Accepted: 18 October 2018

\begin{abstract}
Objective: In this review, we report antimicrobial candidates containing pyrazole nucleus integrated with various functionalities.

Methods: research results by numerous scientists have been summarized from international journals indexed in reputed database such as Scopus and Web of Science.
\end{abstract}

Results: Pyrazole derivatives are much of interest as potent bioactive molecules. They have shown large bioactivities especially antimicrobial performance against broad spectrum of bacterial strains.

Conclusion: Several designed pyrazole derivates possessed good to superior antimicrobial activities.

Keywords: Antimicrobial, Antibacterial, Antifungal, Pyrazole, Bioactive.

(C) 2018 The Authors. Published by Innovare Academic Sciences Pvt Ltd. This is an open access article under the CC BY license (http://creativecommons. org/licenses/by/4. 0/) DOI: http://dx.doi.org/10.22159/ajpcr.2018.v11i12.29418

\section{INTRODUCTION}

Microbial spread and infection as the major cause of illness in human are main problems occurred in both developing and developed countries [1-3]. It leads a large number of dead every year [4,5]. This condition is deteriorated by the emergence of multidrugs resistance (MDR) phenomena. Old antibiotics such as tetracyclines, methicillin, aminoglycosides, macrolides, and penicillin have become less and less effective day by day [6,7]. For example, drug-resistant Mycobacterium tuberculosis and Staphylococcus aureus are found [8,9]. Therefore, continuation in developing antimicrobial agents with an attractive structural motif and activity toward organic synthesis is a great challenge.

Recently, researcher's attention has been paid to heterocycles containing nitrogen atom, particularly pyrazoles and their derivatives [10]. They have been found to denote versatile biological activities such as monoamine oxidase inhibitor [11,12], antihepatotoxicity $[13,14]$, antileishmanial [15-17], anti-inflammatory [18-20], antiproliferative [21], tissue non-specific alkaline phosphatase inhibitor [22], cyclin-dependent kinase inhibitor [23], anticancer [24-27], antimicrobial [28-30], and antioxidant [31-33]. Development of novel chemical structures of pyrazole derivatives is currently a trending topic due to their wonderful biological actions [34-37]. In this paper, we will focus on the diverse structure of pyrazole derivatives and related compounds (e.g. pyrazolines, pyrazolinones, and pyrazolones) synthesized in the past few years and their performance as potent antimicrobial candidates.

\section{DISCUSSION}

\section{Research in 2013}

The synthesis of some new pyrazolopyridines from 4-(dimethylaminomethylene)-1-phenyl-3-(pyridine-3-yl)- $1 H$ pyrazol-5(4H)-one was investigated by El-Borai et al. [38]. Among the synthesized compounds, (1) exhibited remarkable antimicrobial activity against Escherichia coli, Enterobacter cloacae, and Serratia with inhibition zone diameter of 19,19 , and $17 \mathrm{~nm}$ (at $10 \mathrm{mg} / \mathrm{ml}$ sample concentration), respectively [Fig. 1]. Gaikwad et al. developed three series of thiazole-substituted pyrazole derivatives and investigated their antimicrobial potency [39]. The result highlighted that compound (2) exhibited strong activity against all the tested organism. However, compound (3)-(6) showed good action against $S$. aureus with inhibition values of $24.41-27.13 \mathrm{~mm}$ (at $128 \mu \mathrm{g} / \mathrm{ml}$ ). Introduction of $\mathrm{F}, \mathrm{Cl}, \mathrm{Br}$, and $\mathrm{NO}_{2}$ groups to the phenyl ring enhanced antibacterial and antifungal capability [38]. Preparation and characterization of novel sulphapiperazine containing arylazopyrazoles were performed by Shah et al. [40]. Through antibacterial evaluation, $50 \mu \mathrm{g} / \mathrm{ml}$ of compound (7) resulted inhibition zone diameter of 84, 54, 80, 67, and $70 \mathrm{~mm}$ against Bacillus subtilis, S. aureus, Salmonella typhi, and E. coli, respectively. It was denoted as the most active agent in this series. At $1000 \mu \mathrm{g} / \mathrm{ml}$, compound (7) also showed the highest antifungal activity with an inhibition zone of 78, 76, 77, 66, and $64 \mathrm{~mm}$ against Penicillium expansum, B. theobromine, Nigrosspora sp., Trichothesium sp., and R. nigricun, respectively [40].

A novel bioactive thiazolyl-pyrazoline derivatives were designed by Sharifzadeh et al. through one-pot three-component reactions [41]. Compounds (8) and (9) were noted to have moderate activity against Pseudomonas aeruginosa with inhibition zone diameter of $19 \mathrm{~mm}$ at sample concentration of $1000 \mu \mathrm{g} / \mathrm{ml}$. Three series of new 1,2,4-triazoles and benzoxazoles containing pyrazole moiety were investigated in term of their antimicrobial performance [42]. Among the screened products, compounds (10) and (11) which contain 2, 5-dichlorothiophene and 2, 4-dichlorophenyl substituent, respectively, on pyrazole ring emerged as potent antimicrobial agents. These compounds have minimum inhibition concentration (MIC) values in the range of 1.6125-6.2500 $\mu \mathrm{g} / \mathrm{ml}$ against five tested microbes. Some new pyrazolinone and pyrazole analogs containing quinoline nucleus were synthesized by Amir et al. [43]. From antimicrobial evaluation result, compound (12) was denoted as the most excellent agent with MIC values of $6.25 \mu \mathrm{g} /$ $\mathrm{ml}$ (against E. coli, Aspergillus niger, and Candida albicans) and $12.5 \mu \mathrm{g} /$ $\mathrm{ml}$ (against $S$. aureus). Compounds bearing electron withdrawing group such as fluoro and bromo at phenyl ring substituent of pyrazolinone and pyrazole nucleus showed better activity than compounds with electron donating group [43]. Compound (13) was chosen as the most potent antimicrobial agent in a new series of 6-amino-1-(1,3-diphenyl- $1 \mathrm{H}$ pyrazole-4-yl)methyleneamino)-4-(aryl)-2-oxo-1,2-dihydropyridine3,5-dicarbonitriles [44]. The synthesis of some novel pyrazole and pyrazole derivatives bearing benzensulfonamide moiety was done by Hassan [45]. Compound (14) exhibited the highest activity against C. albicans strains with MIC value of $12.5 \mu \mathrm{g} / \mathrm{ml}$. New derivatives of 
pyrazole-3-carboxylates, 1, 3, 4-oxadiazoles and 5-aminopyrazole-4carboxylates were synthesized by Siddiqui et al. [46]. Furthermore, 12 novel compounds were also screened for their antimicrobial efficacy. Compound (15) was observed to denote significant activity against A. niger with MIC value of $12.5 \mu \mathrm{g} / \mathrm{ml}$. It has the same performance with standard drug clotrimazole.

\section{Research in 2014}

A new series of 2- $H$ /methyl-3-phenyl-5-alkyl/aryl/heteroaryl-7trifluoromethylpyrazolo $(1,5-a)$ pyrimidines were developed by Aggarwal et al. and were tested for their antimicrobial activity [47]. All tested compounds possessed moderate antibacterial activity against $S$. aureus and B. subtilis as Gram-positive bacteria [Fig. 2]. Among them, compounds (16) and (17) were selected as the most potent agent with inhibition zone diameter between 15.6 and $19.3 \mathrm{~mm}$. Kumar et al. synthesized some new pyrimidine pyrazole heterocycles [48]. Following antifungal evaluation, compounds (18) and (19) showed synergy with standard drug ketoconazole at 1:8 $(6.25: 50.0 \mu \mathrm{g} / \mathrm{ml})$ and 1:4 (25:100 $\mu \mathrm{g} / \mathrm{ml})$ against Aspergillus fumigatus (ITCC 4517) and A. fumigatus (VPCI 190/96), respectively.

Lavanya et al. reported the synthesis of some novel (1,4-phenylene) bis (arylsulfonylpyrazoles and isoxazoles) by 1,3-dipolar cycloaddition of nitrile imines and nitrile oxides [49]. In pyrazole series, compound (20) exhibited promising activity against both of Gram-positive and Gram-negative bacteria. However, among the synthesized compounds, the study revealed that compound which contains isoxazole nucleus has better activity than compound with pyrazole ring. Malladi et al. developed new analogs of 2,5-disubstituted-1, 3, 4-oxadiazoles bearing pyrazole skeleton [50]. Following in vitro evaluation of antimicrobial performance, compounds (21) and (22) were noted to have appreciable activity against $E$. coli, $S$. aureus, and P. aeruginosa strains with diameter of zone inhibition in the range of $9-13 \mathrm{~mm}$. These compounds also showed remarkable antifungal activity against different strains of Aspergillus flavus, C. keratinophilum, and C. albicans [50].
One-pot multicomponent synthesis and biological benefit of some new quinazolin-4(3H)-one integrated with 1,3-diphenyl-1H-pyrazole system were studied by Mehta et al. [51]. Among the prepared compounds, compound (23) was chosen as the most prominent agent against some Gram-positive and Gram-negative bacteria. Furthermore, this compound exhibited excellent action as anti-M. tuberculosis with 98\% of inhibition using Rifampicin and Isoniazid as positive controls. From a novel series of 2-(5-methyl-1,3-diphenyl-1H-pyrazole-4-yl)-5phenyl-1,3,4-oxadiazoles developed by Ningaiah et al., compound (24) was selected as the most potent antimicrobial agent [52]. Compound (25) showed most excellent antibacterial activity in a new series of 5-(thiophen-2-yl)-phenyl pyrazolines synthesized by Rani and Mohamad [53]. The hybrid of pyrazole-quinoline-pyridine as a novel class of antimicrobial candidates was developed by Sangani et al. [54]. Based on antimicrobial evaluation in term of MIC values, compounds (26) and (27) were denoted as the most promising candidates. Mishra et al. studied the synthesis and antibacterial action of 3-substituted pyrazole derivatives [55]. Compound (28-30) showed moderate to feeble inhibition against both Gram-positive and Gram-negative bacteria.

\section{Research in 2015}

Polysubstituted and condensed pyrazolopyranopyrimidine and pyrazolopyranotriazine were developed by $\mathrm{Hafez}$ et al. and were subsequently found to exhibit activity against certain microbial strains [56]. Compound (31) was the most active antifungal agent. It has better performance than fluconazole [Fig. 3]. Meanwhile, compound (32) exhibited excellent activity against bacteria which was higher or equal to MIC of norfloxacin [56]. Synthesis and antimicrobial screening of acetyl sulfonamide pyrazoles, substituted 4,5-dihydropyrazole-1carbothioamide and 4,5-dihydropyrazole-1-isonicotinoyl derivatives were presented by Hamada and Abdo [57]. Compound (33) showed most potent activity against $S$. aureus and $C$. albicans with inhibition zones of 21 and $24 \mathrm{~mm}$, respectively. The presence of pharmacophores

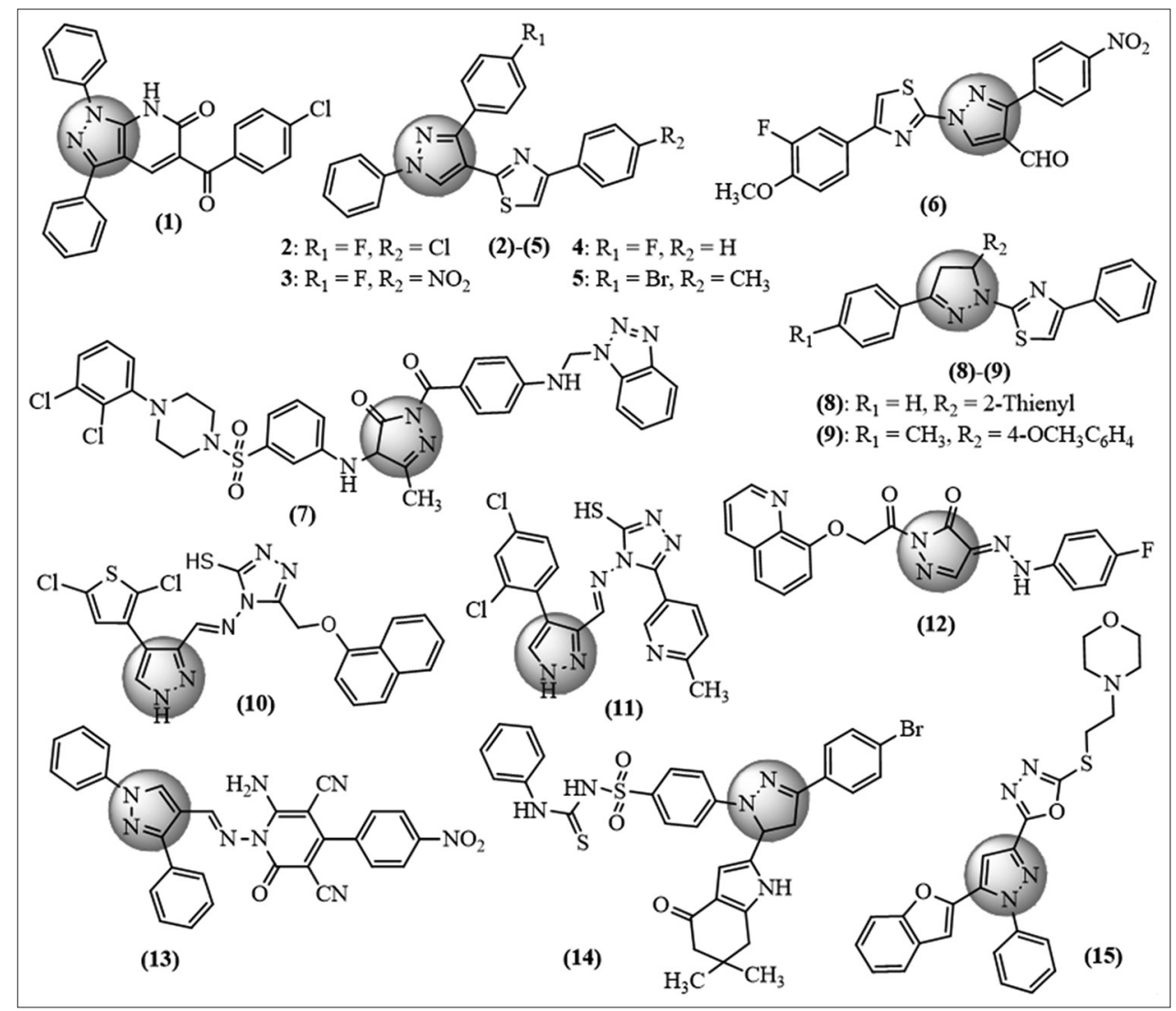

Fig. 1: Structure of compounds (1)-(15) 


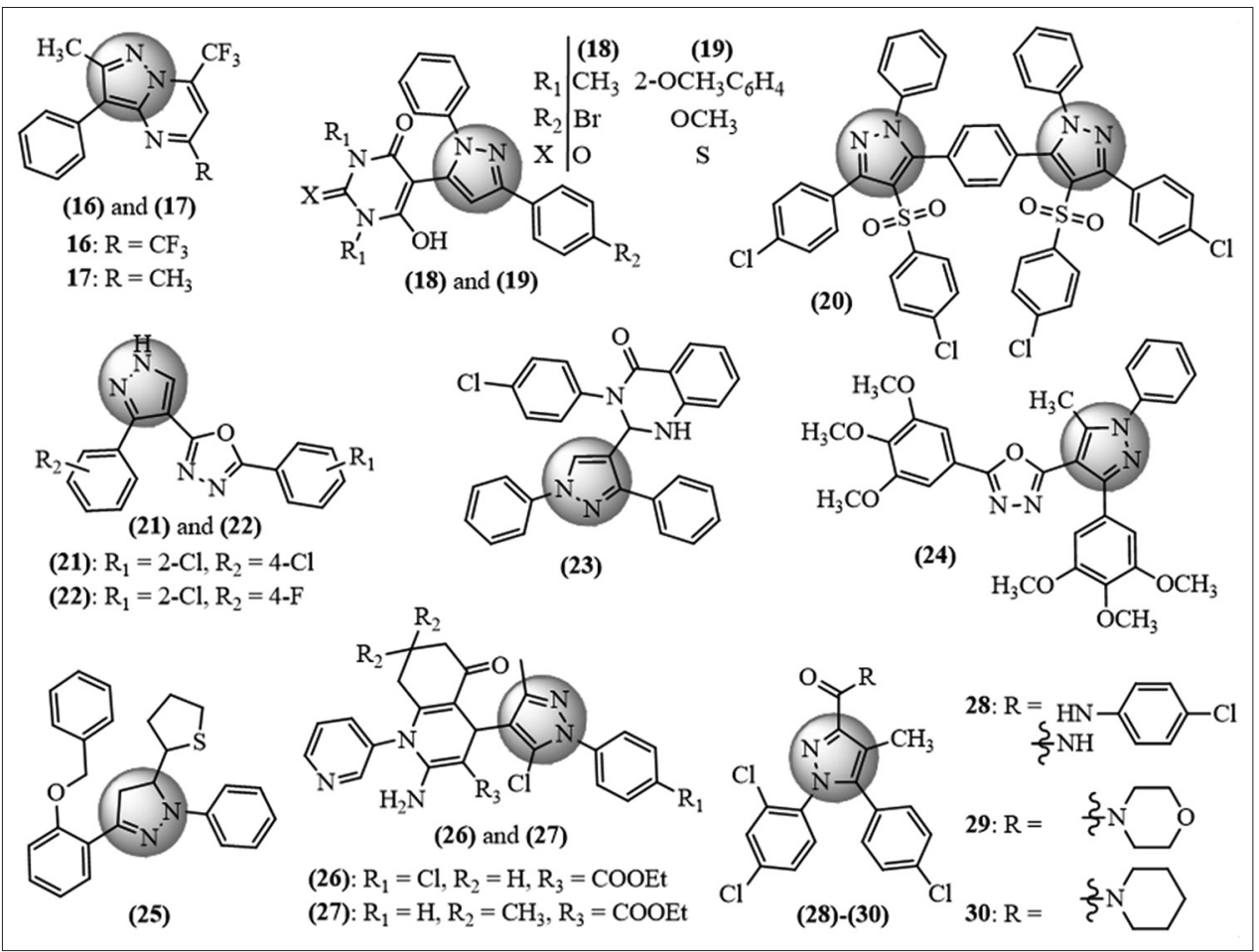

Fig. 2: Structure of compounds (16-30)

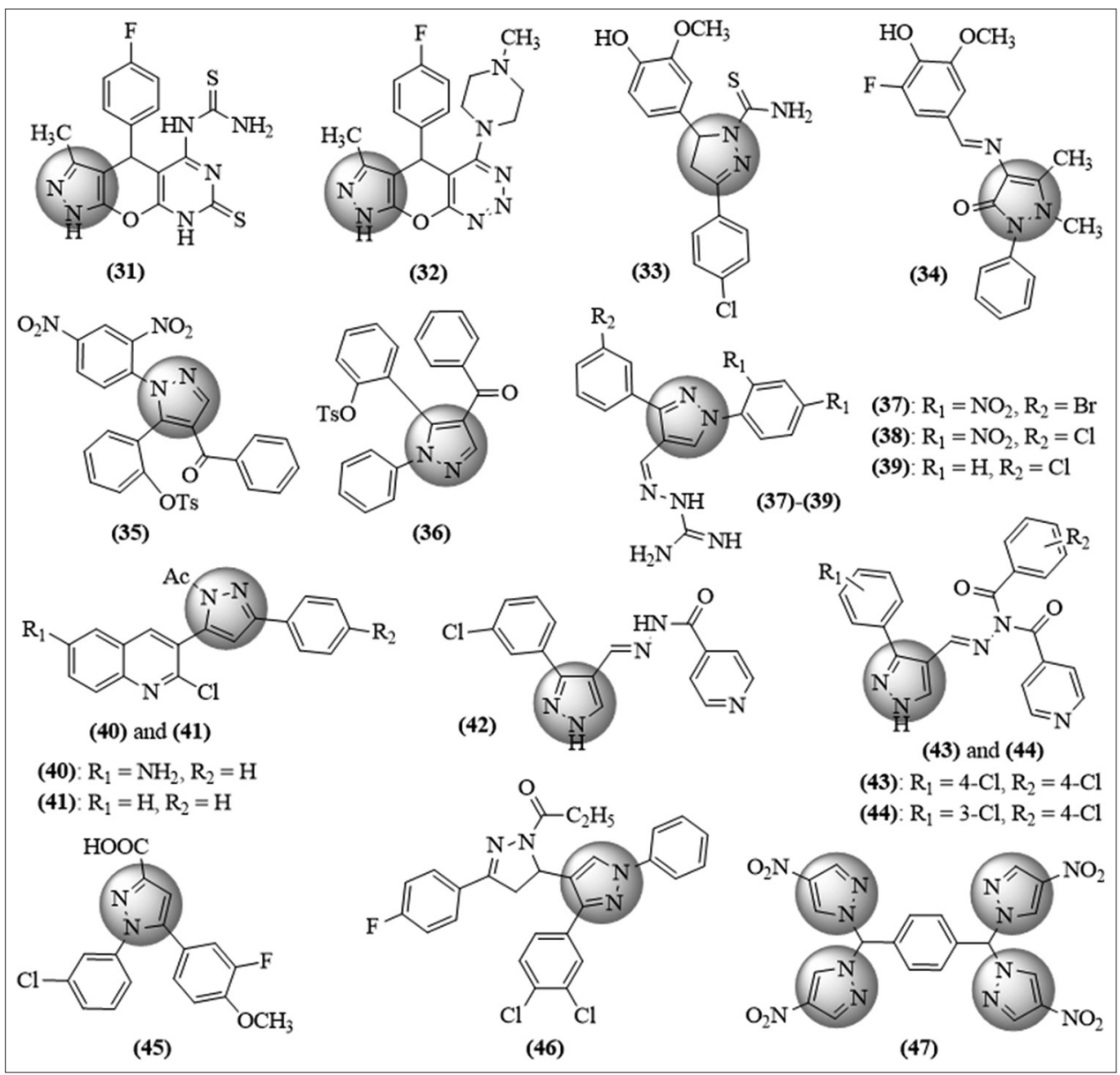

Fig. 3: Structure of compounds (31-47) 
with lipophilic properties such as chloro and bromo enhances the antimicrobial efficacy.

A remarkable antibacterial effect against $S$. pneumoniae, E. faecalis, and H. influenzae of (34) was recorded by İskeleli et al. [58]. Unfortunately, it has no antifungal effect for selected fungal isolates. The multicomponent cyclo-condensation reaction of 1-phenyl-3-(2-(tosyloxy)phenyl) propane-1,3-dione, N,N-dimethylformamide dimethyl acetal and hydrazine or hydroxylamine hydrochloride or 2-aminothiophenol or 2-aminophenol or benzene-1,2-diamine was used to prepare some novel pyrazole, isoxazole, and other heterocyclic models [59]. In pyrazole series, compound (35) was denoted to give appreciable activity against all tested microbes. Compound (36) has similar performance to compound (35) except against fungi Fusarium oxysporum; no effect was observed [59]. Preparation and biological testing of 1,3-diaryl pyrazoles bearing aminoguanidine or furan-2-carbohydrazide functionalities have been done by Li et al. [60]. Most of the prepared compounds exhibited promising action against several Gram-positive and Gramnegative bacteria with MIC values between 1 and $64 \mu \mathrm{g} / \mathrm{ml}$. Specifically, compounds (37-39) were highlighted as the most active candidates against both bacterial and fungal strains with MIC values of 1 or $2 \mu \mathrm{g} / \mathrm{ml}$. A novel series of pyrazoles decorated with 2 -chloroquinoline nucleus have been synthesized and evaluated for antimicrobial activity by Miniyar et al. [61]. Among the series, compound (40) moderately inhibited A. fumigatus, $P$. notatum, and B. subtilis with MIC 48, 46, and $44 \mu \mathrm{g} / \mathrm{ml}$, respectively, whereas compound (41) was noted as an active agent against E. coli, P. notatum, and B. subtilis with MIC 43, 57, and $54 \mu \mathrm{g} / \mathrm{ml}$, respectively [61].

Nayak et al. successfully designed a novel series of isonicotinohydrazide based pyrazole derivatives [62]. Following in vitro evaluation of antibacterial activity, three derivatives (42-44) showed high performance against the tested bacteria having zone inhibition in the range of 15-25 mm. Raundal et al. have synthesized and characterized novel 1,5-disubstituted pyrazole and isoxazole derivatives [63]. All the prepared compounds have been investigated for the antibacterial and antifungal potency. Interestingly, all the tested samples perform good activity, however, compound (45) possess highest performance. In the study conducted by Viveka et al., the design synthesis and antibacterial activity of some novel pyrazolyl-pyrazolines have been developed [64]. The bioactivity test revealed that compound (46) that contains $\mathrm{N}$-propionyl pyrazolyl-pyrazoline could be identified as the most promising candidate for an antibacterial agent with zone inhibition diameter within 15-28 mm against Gram-positive and Gramnegative bacteria. The compounds with multi-pyrazole nucleus and their application as antibacterial agents have been synthesized and evaluated by Wang et al. [65]. Compound (47) was found to be the most active with superior area of zone inhibition of 431.81 and $222.14 \mathrm{~mm} 2$ against $S$. aureus and B. subtilis, respectively.

\section{Research in 2016}

Phenyl-pyrazolines and isoniazid-pyrazolines were prepared by Ahmad et al. starting from $p$-acetamidophenol initial substrate [66]. Newly obtained pyrazolines showed interesting antibacterial activity toward bacterial and fungal strains [Fig. 4]. Specifically, compound (48) exhibited excellent antibacterial potency against $S$. aureus and $P$. aeruginosa with MIC $3.12 \mu \mathrm{g} / \mathrm{mL}$. On the other hand, compound (49) has been identified as the most potent antifungal performance against A. niger and C. albicans (MIC $3.12 \mu \mathrm{g} / \mathrm{mL}$ ) [66]. Akondi et al. described the in water synthesis of pyrazolone derivatives containing 2-naphtol skeleton using $\mathrm{Ce} / \mathrm{SiO}_{2}$ composite catalyst [67]. Overall, compound (50) was recorded as the most potent antimicrobial candidate through in vitro assay against Micrococcus luteus, B. subtilis, Salmonella paratyphi, S. typhi, C. albicans, and Trichoderma viride with zone of inhibition between 20 and $28.5 \mathrm{~mm}$. In addition, it moderately inhibits the growth of S. mutans and P. aeruginosa (14.5 and $13.5 \mathrm{~mm}$, respectively). Pyrazole compounds integrated with 1,4-benzothiazine moiety have been developed by Dabholkar and Gavande [68]. Through antimicrobial assay, compound (51) was found to be the most promising candidate in this series against some Gram-positive, Gram-negative bacteria, and fungi with zone of inhibition in the range of $10-17 \mathrm{~mm}$.

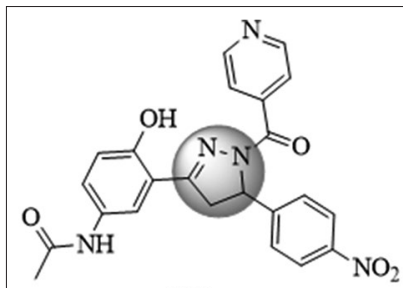

(48)<smiles>Cc1cccc2cc(Cl)ccc12</smiles>

(51)<smiles>Cc1cc(N)c2cccc(C(F)(F)F)c2n1</smiles><smiles>Cc1ccc(C2=C(C=NI)C=NCC2)cc1</smiles>

(57)<smiles></smiles>

(49)<smiles>Cc1nc(-c2ccc(Cl)cc2)c2nc(N)c(=O)n(N)c2n1</smiles>

(52)<smiles></smiles>

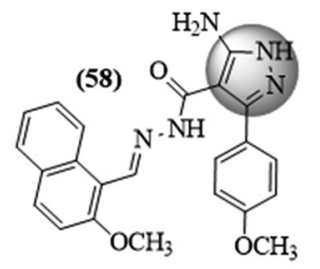<smiles>Cc1cc(N)c2cccc(C(F)(F)F)c2n1</smiles>

(56)

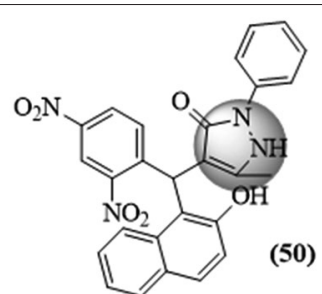

$\mathrm{HO}$

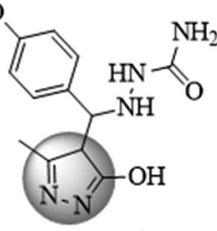

(53)

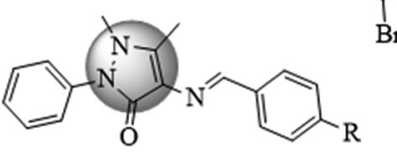

(59) $\mathrm{R}=\mathrm{Cl}$

(60) $\mathrm{R}=\mathrm{NO}_{2}$

Fig. 4: Structure of compounds (48-60) 


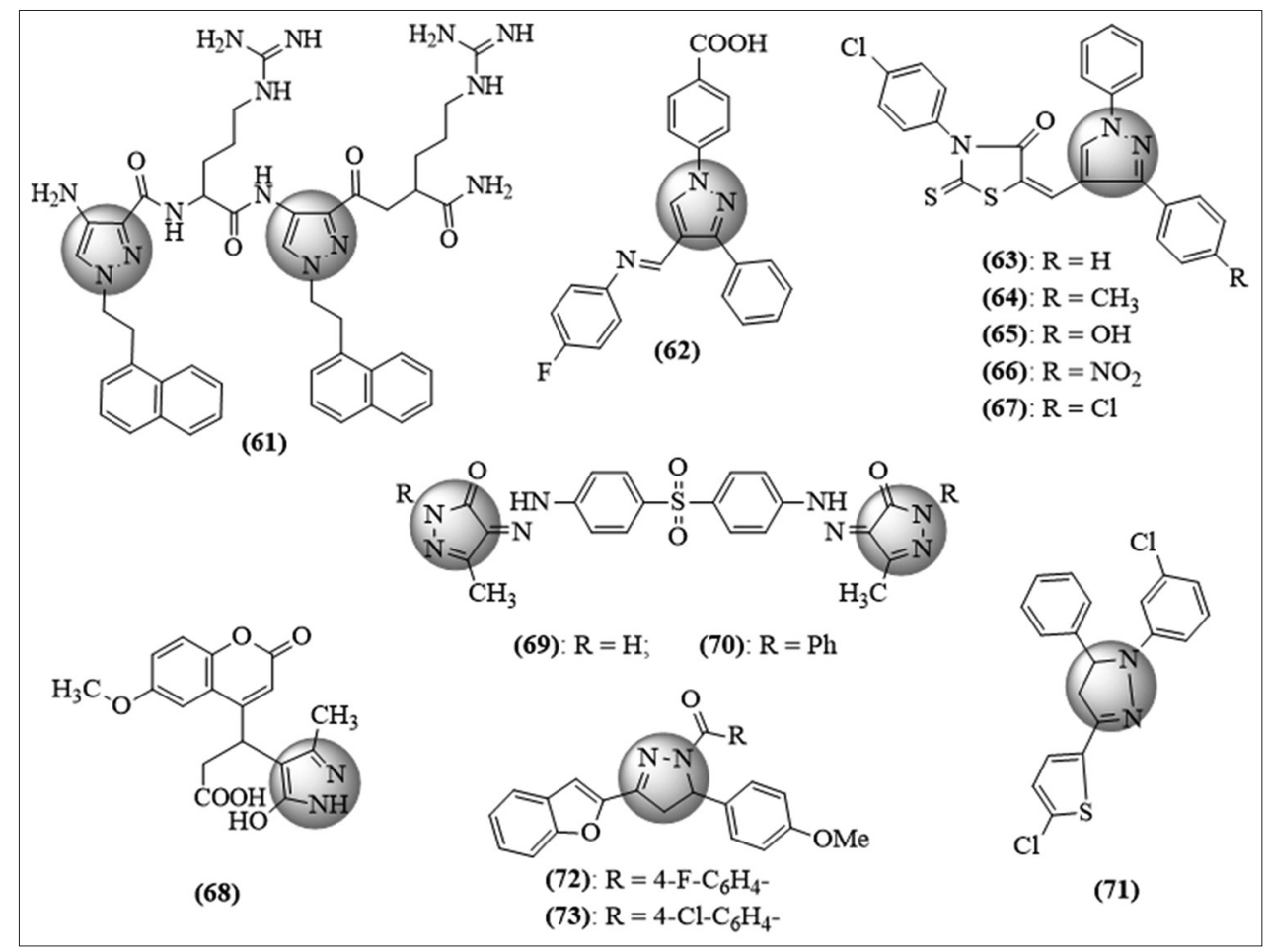

Fig. 5: Structure of compounds (61-73)

Antimicrobial assessment was carried out for newly synthesized pyrazole derivatives containing oxa/thiadiazolyl or pyrazolyl moieties and pyrazolopyrimidine derivatives [69]. Among the prepared compounds, there were seven candidates that showed excellent activity compared to standard drug. However, compound (52) was selected as the best agent. Surendra Kumar et al. explored the synthesis of novel pyrazole analogs and screened them for antimicrobial potency [70]. Compound (53) was found to be the most promising candidate against Gram-negative bacterial strain of E. coli (MIC $0.25 \mu \mathrm{g} / \mathrm{mL}$ and zone of inhibition $28 \mathrm{~mm}$ ). Quinoline-pyrazole hybrid derivatives containing fluorine moiety were synthesized and screened for antibacterial activity by Nayak et al. [71]. From in vitro test, it was found that compound (54-57) exhibited substantial inhibitory activity against bacterial strains with inhibition zone diameter within 15-24 mm. Refat and Fadda reported the synthesis and antimicrobial activity of some novel hydrazide, pyrazole, triazine, isoxazole, and pyrimidine derivatives [72]. Surprisingly, pyrazole (58) was denoted as the most potent compound within this research result. It could be concluded that pyrazole is one of the lead compounds for antimicrobial agent. A series of Schiff's bases of substituted (4E)-4-(benzylideneamino)1,2-dihydro-2,3-dimethyl-1-phenylpyrazol-5-ones have been prepared starting from 4-AAP and benzaldehyde derivatives [73]. Based on Kirby-Bauer protocol for antimicrobial assay, it was noted that compounds (59) and (60) exhibited the high activity against bacterial as well as fungal strains, such as B. subtilis, $P$. aeruginosa, and A. niger. Schiff's bases containing 4-Cl and 4- $\mathrm{NO}_{2}$ moieties presented good inhibitory activity [73].

\section{Research in 2017}

Ahn et al. reported the first route to pyrazole-arginine derived from novel synthesized $\mathrm{N}$-alkyl/aryl pyrazole amino acids [74]. Compound (61) proved to be a promising lead compound of antimicrobial agent against MDR bacteria, such as methicillin-resistant $S$. aureus (MRSA), MDR P. aeruginosa (MDRPA), and vancomycin-resistant Enterococcus faecium (VREF) strains [Fig. 5]. Compared to melittin as reference drug, it showed 2-folds, 2-4-folds, and 4-folds of better activity against MRSA, MDRPA, and VREF, respectively. A superior antimicrobial activity with zone of growth inhibition up to $85 \mathrm{~mm}$ against Acinetobacter baumannii was displayed by 4-(4-formyl-3-phenyl-1H-pyrazol-1-yl) benzoic acid, a compound in a series prepared by Allison et al. [75]. A new series of pyrazole derivatives containing 2-thioxothiazolidine-4one were studied by Bhatt and Sharma [76]. Antimicrobial evaluation of the synthesized products revealed that compounds (63-65) were found as promising candidate for anti-S. aureus activity. Furthermore, compound (66) showed a potent activity against E. coli strains. Meanwhile, a very good activity against $C$. albicans was showed by compound (64) and (67). Chougala et al. developed an eco-friendly and green method of multicomponent reaction for the synthesis of coumarin-based pyrano [2,3-c]pyrazole derivatives [77]. All synthesized compounds have shown the interesting result to be drug candidates. Compound (68) was found having excellent activity against Gram-positive and Gram-negative bacteria (minimum inhibitory concentration [MIC] 0.78-6.25 $\mu \mathrm{g} / \mathrm{mL}$ ).

Mehta et al. developed new mono and bisphenyl integrated bispyrazole and bispyrazolone derivatives, then evaluated their antimicrobial performance [78]. Compound (69) and (70) demonstrated good inhibitory activity against some bacterial strains with zone of inhibition in the range of 19-27 $\mathrm{mm}$. The title compound 1-(3-chlorophenyl)-3-(5-chlorothiophen-2-yl)-5-phenyl-4,5-dihydro$1 \mathrm{H}$-pyrazole was prepared and screened for antimicrobial activity by Prabhudeva et al. [79]. In vitro test of the ligand (71) revealed that this compound has moderate inhibitory activity against B. subtilis and A. flavus. Meanwhile, against $S$. aureus and E. coli, it showed good performance with MIC $20 \mu \mathrm{g} / \mathrm{mL}$, same with Streptomycin as positive control. A novel class of 3-(benzofuran-2-yl)-5-(4-methoxyphenyl)4,5-dihydro- $1 H$-pyrazole derivatives was designed by Rangaswamy et al. [80]. Using well plate method for antimicrobial assay, compound (72) and (73) exhibited good inhibitory activity against E. coli, S. aureus, and P. aeruginosa.

\section{CONCLUSION}

Several developed pyrazole derivatives possessed good to superior antimicrobial activities. This current review provides important information for the upcoming design of new antimicrobial agents based pyrazole skeleton. 


\section{CONFLICTS OF INTEREST}

There are no conflicts of interest.

\section{AUTHORS' CONTRIBUTION}

Bayu Ardiansah responsible for collecting data from literatures and writing the manuscript.

\section{REFERENCES}

1. Raghavan S, Alagarasu K, Selvaraj P. Immunogenetics of HIV and HIV associated tuberculosis. Tuberculosis (Edinb) 2012;92:18-30.

2. de Oliviera DR, Tintino SR, Braga MF, Boligon AA, Athayde ML, Coutinho HD, et al. In vitro antimicrobial and modulatory activity of the natural products silymarin and silibinin. BioMed Res Int 2015;2015:7.

3. Phillips DJ, Harrison J, Richards SJ, Mitchell DE, Tichauer E, Hubbard AT, et al. Evaluation of the antimicrobial activity of cationic polymers against mycobacteria: Toward antitubercular macromolecules. Biomacromolecules 2017;18:1592-9.

4. Gabriel GJ, Som A, Madkour AE, Eren T, Tew GN. Infectious disease: Connecting innate immunity to biocidal polymers. Mater Sci Eng R Rep 2007;57:28-64.

5. Tuchilus CG, Nichifor M, Mocanu G, Stanciu MC. Antimicrobial activity of chemically modified dextran derivatives. Carbohydr Polym 2017;161:181-6.

6. Balouiri M, Sadiki M, Ibnsouda SK. Methods for in vitro evaluating antimicrobial activity: A review. J Pharm Anal 2016;6:71-9.

7. Pisal P, Deodhar M, Kale A, Nigade G, Pawar S. Design, synthesis, docking studies and biological evaluation of 2-phenyl-3-(substituted benzo[d] thiazol-2-ylamino)-quinazoline-4(3H)-one derivatives as antimicrobial agents. Int J Pharm Pharm Sci 2018;10:57.

8. Zaffiri L, Gardner J, Toledo-Pereyra LH. History of antibiotics. From salvarsan to cephalosporins. J Invest Surg 2012;25:67-77.

9. Abd-El Aal AM, El-Hadidy MR, El-Mashad NB, El-Sebaie AH. Antimicrobial effect of bee honey in comparison to antibiotics on organisms isolated from infected burns. Ann Burns Fire Disasters 2007;20:83-8

10. Gurunanjappa P, Nagamallu R, Kariyappa AK. Synthesis and antimicrobial activity of novel fused pyrazoles. Int J Pharm Pharm Sci 2015;7:379.

11. Chimenti F, Carradori S, Secci D, Bolasco A, Bizzarri B, Chimenti P, et al. Synthesis and inhibitory activity against human monoamine oxidase of N1-thiocarbamoyl-3,5-di(hetero)aryl-4,5-dihydro- $(1 \mathrm{H})$ pyrazole derivatives. Eur J Med Chem 2010;45:800-4.

12. Peyssonnaux $C$, Eychène $A$. The raf/MEK/ERK pathway: New concepts of activation. Biol Cell 2001;93:53-62.

13. Khan SA, Ahmad B, Alam T. Synthesis and antihepatotoxic activity of some new chalcones containing 1, 4-dioxane ring system. Pak J Pharm Sci 2006;19:290-4

14. Khalilullah H, Khan S, Ahsan MJ, Ahmed B. Synthesis and antihepatotoxic activity of 5-(2,3-dihydro-1,4-benzodioxane-6-yl)-3substituted-phenyl-4,5-dihydro-1H-pyrazole derivatives. Bioorg Med Chem Lett 2011;21:7251-4.

15. dos Santos MS, Oliveira ML, Bernardino AM, de Léo RM, Amaral VF, de Carvalho FT, et al. Synthesis and antileishmanial evaluation of 1-aryl-4-(4,5-dihydro-1H-imidazol-2-yl)-1H-pyrazole derivatives. Bioorg Med Chem Lett 2011;21:7451-4.

16. Dardari Z, Lemrani M, Sebban A, Bahloul A, Hassar M, Kitane S, et al. Antileishmanial and antibacterial activity of a new pyrazole derivative designated 4-[2-(1-(ethylamino)-2-methyl- propyl)phenyl]3-(4-methyphenyl)-1-phenylpyrazole. Arch Pharm (Weinheim) 2006;339:291-8.

17. Dos Santos MS, Gomes AO, Bernardino AM, de Souza MC, Khan MA, de Brito MA, et al. Synthesis and antileishmanial activity of new 1-aryl-1H-pyrazole-4-carboximidamides derivatives. J Braz Chem Soc 2011;22:352

18. Kendre BV, Landge MG, Jadhav WN, Bhusare SR. Synthesis and bioactivities of some new $1 \mathrm{H}$-pyrazole derivatives containing an aryl sulfonate moiety. Chin Chem Lett 2013;24:325.

19. Malladi S, Isloor AM, Shetty P, Fun HK, Telkar S, Mahmoud R, et al. Synthesis and anti-inflammatory evaluation of some new 3, 6-disubstituted-1, 2, 4-triazolo-[3, 4-b]-1, 3, 4-thiadiazoles bearing pyrazole moiety. Med Chem Res 2012;21:3272.

20. Tewari AK, Singh VP, Yadav P, Gupta G, Singh A, Goel RK, et al. Synthesis, biological evaluation and molecular modeling study of pyrazole derivatives as selective COX-2 inhibitors and anti- inflammatory agents. Bioorg Chem 2014;56:8-15.

21. Huang YY, Wang LY, Chang CH, Kuo YK, Kaneko K, Takayama H, et al. One-pot synthesis and antiproliferative evaluation of pyrazolo[3,4-d] pyrimidine derivatives. Tetrahedron 2012;68:9658.

22. Sidique S, Ardecky R, Su Y, Narisawa S, Brown B, Millán JL, et al. Design and synthesis of pyrazole derivatives as potent and selective inhibitors of tissue-nonspecific alkaline phosphatase (TNAP). Bioorg Med Chem Lett 2009;19:222-5.

23. Sun J, Lv XH, Qiu HY, Wang YT, Du QR, Li DD, et al. Synthesis, biological evaluation and molecular docking studies of pyrazole derivatives coupling with a thiourea moiety as novel CDKs inhibitors. Eur J Med Chem 2013;68:1.

24. Inceler N, Yilmaz A, Baytas SN. Synthesis of ester and amide derivatives of 1-phenyl-3-(thiophen-3-yl)-1H-pyrazole-4-carboxylic acid and study of their anticancer activity. Med Chem Res 2013;22:3109.

25. Nitulescu GM, Draghici C, Missir AV. Synthesis of new pyrazole derivatives and their anticancer evaluation. Eur J Med Chem 2010;45:4914-9.

26. Prasad YR, Kumar GV, Chandrashekar SM. Synthesis and biological evaluation of novel 4,5-dihydropyrazole derivatives as potent anticancer and antimicrobial agents. Med Chem Res 2013;22:2061.

27. Rai U, Isloor AM, Shetty P, Pai KS, Fun HK. Synthesis and in vitro biological evaluation of new pyrazole chalcones and heterocyclic diamides as potential anticancer agents. Arabian J Chem 2015;8:317.

28. Chandna N, Kapoor JK, Grover J, Bairwa K, Goyal V, Jachak SM. Pyrazolylbenzyltriazoles as cyclooxygenase inhibitors: Synthesis and biological evaluation as dual anti-inflammatory and antimicrobial agents. New J Chem 2014;38:3662.

29. Vijesh AM, Isloor AM, Telkar S, Peethambar SK, Rai S, Isloor N, et al. Synthesis, characterization and antimicrobial studies of some new pyrazole incorporated imidazole derivatives. Eur J Med Chem 2011;46:3531-6.

30. Thumar NJ, Patel MP. Synthesis, characterization and biological activity of some new carbostyril bearing $1 \mathrm{H}$-pyrazole moiety. Med Chem Res 2012;21:1751-61.

31. Ambethkar S, Padmini V, Bhuvanesh N. A green and efficient protocol for the synthesis of dihydropyrano[2,3-c]pyrazole derivatives via a one-pot, four component reaction by grinding method. J Adv Res 2015;6:975-85.

32. Mardiana L, Bakri R, Septiarti A, Ardiansah B. The synthesis of 2-(5-(3-methoxyphenyl)-4,5-dihydro-1H-pyrazol-3-yl)phenol using sodium impregnated on activated chicken eggshells catalyst. IOP Conf Ser Mater Sci Eng 2017;188:12022.

33. Gressler V, Moura S, Flores FC, Flores DC, Colepicolo P, Pinto E. Antioxidant and antimicrobial properties of 2-(4,5-Dihydro-1H-pyrazol1-yl)-pyrimidine and 1-carboxamidino-1H-pyrazole derivatives. J Braz Chem Soc 2010;21:1477-83.

34. Sankaran M, Uvarani C, Chandraprakash K, Umamaheswari M, Mohan PS. Antioxidant and antimicrobial properties of 2-(4,5-Dihydro1H-pyrazol-1-yl)-pyrimidine and 1-carboxamidino-1H-pyrazole derivatives. J Heterocycl Chem 2015;52:1082.

35. Kang Z, Wang Y, Zhou L, Zhang M, Song L, Deng H. A facile and consecutive approach to trifluoromethylated spirochromeno[2,3-c]-6HPyrazol-2',5-dione derivatives. J Fluorine Chem 2016;188:131.

36. Gadhave AG, Uphade BK. Synthesis of some pyrazole containing chalcones and pyridine-3-carbonitirles and study of their antiinflammatory activity. Orient J Chem 2017;33:219.

37. Kakarla RK, Vinnakota S, Rani BS, Swethanjali M, Golla NS. Synthesis and structural elucidation of some novel pyrazolin-5-ones. Rasayan J Chem 2016;9:227.

38. El-Borai MA, Rizk HF, Beltagy DM, El-Deeb IY. Microwave-assisted synthesis of some new pyrazolopyridines and their antioxidant, antitumor and antimicrobial activities. Eur J Med Chem 2013;66:415.

39. Gaikwad ND, Patil SV, Bobade VD. Synthesis and antimicrobial activity of novel thiazole substituted pyrazole derivatives. J Heterocycl Chem 2013;50:519-27.

40. Shah PJ, Patel HS, Patel BP. Synthesis, characterization and antimicrobial activity of novel sulphapiperazine containing arylazopyrazoles. J Saudi Chem Soc 2013;17:307-13.

41. Sharifzadeh B, Mahmoodi NO, Mamaghani M, Tabatabaeian K, Chirani AS, Nikokar I, et al. Facile regioselective synthesis of novel bioactive thiazolyl-pyrazoline derivatives via a three-component reaction and their antimicrobial activity. Bioorg Med Chem Lett 2013;23:548-51.

42. Vijesh AM, Isloor AM, Shetty P, Sundershan S, Fun HK. New pyrazole derivatives containing 1,2,4-triazoles and benzoxazoles as potent antimicrobial and analgesic agents. Eur J Med Chem 2013;62:410-5. 
43. Amir M, Javed SA, Hassan MZ. Synthesis and antimicrobial activity of pyrazolinone and pyrazole analogues containing quinoline moiety. Indian J Chem 2013;52B:1493-9.

44. Desai NC, Rajpara KM, Joshi VV. Synthesis of pyrazole encompassing 2-pyridone derivatives as antibacterial agents. Bioorg Med Chem Lett 2013;23:2714-7.

45. Hassan SY. Synthesis, antibacterial and antifungal activity of some new pyrazoline and pyrazole derivatives. Molecules 2013;18:2683-711.

46. Siddiqui NJ, Idrees M, Khati NT, Dhonde MG. Synthesis and antimicrobial activities of some new pyrazoles, oxadiazoles and isoxazole bearing benzofuran moiety. South Afr J Chem 2013;66:248.

47. Aggarwal R, Masan E, Kaushik P, Kaushik D, Sharma C, Aneja KR. Synthesis and biological evaluation of 7-trifluoromethylpyrazolo $[1,5-\mathrm{a}]$ pyrimidines as anti-inflammatory and antimicrobial agents. J Fluorine Chem 2014;168:16.

48. Kumar R, Arora J, Ruhil S, Phougat N, Chhillar AK, Prasad AK. Synthesis and antimicrobial studies of pyrimidine pyrazole heterocycles. Adv Chem 2014;2014:12.

49. Lavanya G, Mallikarjuna Reddy L, Padmavathi V, Padmaja A. Synthesis and antimicrobial activity of (1,4-phenylene)bis(arylsulfonylpyrazoles and isoxazoles). Eur J Med Chem 2014;73:187-94.

50. Malladi S, Isloor AM, Peethambar SK, Fun HK. Synthesis and biological evaluation of newer analogues of 2,5-disubstituted 1,3,4-oxadiazole containing pyrazole moiety as antimicrobial agents. Arabian J Chem 2014; $7: 1185$

51. Mehta HB, Dixit BC, Dixit RB. L-Proline catalyzed one-pot multi-component synthesis of 2-(1, 3-diphenyl-1H-pyrazol-4-yl) quinazolin-4 $(3 \mathrm{H})$-one derivatives and their biological studies. Chin Chem Lett 2014;25:741.

52. Ningaiah S, Bhadraiah UK, Doddaramappa SD, Keshavamurthy S, Javarasetty C. Novel pyrazole integrated 1,3,4-oxadiazoles: Synthesis, characterization and antimicrobial evaluation. Bioorg Med Chem Lett 2014;24:245-8.

53. Rani M, Mohamad Y. Synthesis, studies and in vitro antibacterial activity of some 5-(thiophene-2-yl)-phenyl pyrazoline derivatives. J Saudi Chem Soc 2014;18:411-7.

54. Sangani CB, Makawana JA, Zhang X, Teraiya SB, Lin L, Zhu HL. Design, synthesis and molecular modeling of pyrazole-quinolinepyridine hybrids as a new class of antimicrobial and anticancer agents. Eur J Med Chem 2014;76:549.

55. Mishra SK, Majumdar P, Behera RK, Behera AK. Synthesis of 3 -substituted pyrazole derivatives by mixed anhydride method and study of their antibacterial activities. Synth Commun 2014;44:32.

56. Hafez HN, Alshammari AG, El-Gazzar AR. Facile heterocyclic synthesis and antimicrobial activity of polysubstituted and condensed pyrazolopyranopyrimidine and pyrazolopyranotriazine derivatives. Acta Pharm 2015;65:399-412.

57. Hamada MM, Abdo YM. Synthesis, characterization, antimicrobial screening and free-radical scavenging activity of some novel substituted pyrazoles. Molecules 2015;20:10468-86.

58. İskeleli NO, Alpaslan YB, Direkel Ş, Ertürk AG, Süleymanoğlu N, Ustabas R, et al. The new schiff base 4-[(4-hydroxy-3-fluoro-5methoxy-benzylidene)amino]-1,5-dimethyl-2-phenyl-1,2-dihydropyrazol-3-one: Experimental, DFT calculational studies and in vitro antimicrobial activity. Spectrochim Acta A Mol Biomol Spectrosc 2015;139:356-66.

59. Kendre BV, Landge MG, Bhusare SR. Synthesis and biological evaluation of some novel pyrazole, isoxazole, benzoxazepine, benzothiazepine and benzodiazepine derivatives bearing an aryl sulfonate moiety as antimicrobial and anti-inflammatory agents. Arabian J Chem 2015;20:30.

60. Li YR, Li C, Liu JC, Guo M, Zhang TY, Sun LP, et al. Synthesis and biological evaluation of 1,3-diaryl pyrazole derivatives as potential antibacterial and anti-inflammatory agents. Bioorg Med Chem Lett 2015;25:5052-7.

61. Miniyar PB, Barmade MA, Mahajan AA. Synthesis and biological evaluation of 1-(5-(2-chloroquinolin-3-yl)-3-phenyl-1H-pyrazol-1-yl) ethanone derivatives as potential antimicrobial agents. J Saudi Chem Soc 2015;19:655-60.
62. Nayak N, Ramprasad J, Dalimba U. New INH-pyrazole analogs: Design, synthesis and evaluation of antitubercular and antibacterial activity. Bioorg Med Chem Lett 2015;25:5540.

63. Raundal HN, Jadhav RP, Patil AA, Bobade VD. Synthesis andbiological screening of novel pyrazole and isoxazole derivatives. Indian J Chem 2015;54B:979-87.

64. Viveka S, Shama DP, Nagaraja GK, Ballav S, Kerkar S. Design and synthesis of some new pyrazolyl-pyrazolines as potential antiinflammatory, analgesic and antibacterial agents. Eur J Med Chem 2015;101:442-51.

65. Wang JX, Zhu ZR, Bai FY, Wang XY, Zhang XX, Xing YH. Molecular design and the optimum synthetic route of the compounds with multipyrazole and its derivatives and the potential application in antibacterial agents Polyhedron. Polyhedron 2015;99:59.

66. Ahmad A, Husain A, Khan SA, Mujeeb M, Bhandari A. Synthesis, antimicrobial and antitubercular activities of some novel pyrazoline derivatives. J Saudi Chem Soc 2016;20:577-84

67. Akondi AM, Kantam ML, Trivedi R, Bharatam J, Vemulapalli PB, Bhargava $\mathrm{SK}$, et al. $\mathrm{Ce} / \mathrm{SiO}_{2}$ composite as an efficient catalyst for the multicomponent one-pot synthesis of substituted pyrazolones in aqueous media and their antimicrobial activities. J Mol Catal A Chem 2016;411:325-36.

68. Dabholkar VV, Gavande RP. Synthesis and antimicrobial activities of novel 1,4-benzothiazine derivatives. Arabian J Chem 2016;9:S225-9.

69. Hafez HN, El-Gazzar BA, Al-Hussain SA. Novel pyrazole derivatives with oxa/thiadiazolyl, pyrazolyl moieties and pyrazolo [4, 3-d]pyrimidine derivatives as potential antimicrobial and anticancer agents. Bioor Med Chem Lett 2016;26:2428-33.

70. Surendra Kumar R, Arif IA, Ahamed A, Idhayadhulla A. Antiinflammatory and antimicrobial activities of novel pyrazole analogues. Saudi J Biol Sci 2016;23:614-20.

71. Nayak N, Ramprasad J, Dalimba U. Synthesis and antitubercular and antibacterial activity of some activefluorine containing quinolinepyrazole hybrid derivatives. J Fluor Chem 2016;183:59-68.

72. Refat HM, Fadda AA. Synthesis and antimicrobial activity of some novel hydrazide, pyrazole, triazine, isoxazole and pyrimidine derivatives. J Heterocycl Chem 2016;53:1129-37.

73. Senbagam R, Vijayakumar R, Rajarajan M, Balaji S, Manikandan V, Vanangamudi G, et al. Synthesis, assessment of substituent effect and antimicrobial activities of (4E)-4-(benzylideneamino)-1,2-dihydro-2,3dimethyl-1-phenylpyrazol-5-one compounds. Karbala Int J Mod Sci 2016:2:56.

74. Ahn M, Gunasekaran P, Rajasekaran G, Kim EY, Lee SJ, Bang G, et al. Pyrazole derived ultra-short antimicrobial peptidomimetics with potent anti-biofilm activity. Eur J Med Chem 2017;125:551-64.

75. Allison D, Delancey E, Ramey H, Williams C, Alsharif ZA, AlKhattabi $\mathrm{H}$, et al. Synthesis and antimicrobial studies of novel derivatives of 4-(4-formyl-3-phenyl-1H-pyrazol-1-yl)benzoic acid as potent anti-Acinetobacter baumannii agents. Bioorg Med Chem Lett 2017;27:387-92.

76. Bhatt HB, Sharma S. Synthesis and antimicrobial activity of pyrazole nucleus containing 2-thioxothiazolidin-4-one derivatives. Arabian J Chem 2017; 10:S1590-6.

77. Chougala BM, Samundeeswari S, Holiyachi M, Shastri LA, Dodamani $\mathrm{S}$, Jalalpure $\mathrm{S}$, et al. Synthesis, characterization and molecular docking studies of substituted 4-coumarinylpyrano[2,3-c]pyrazole derivatives as potent antibacterial and anti-inflammatory agents. Eur J Med Chem 2017;125:101-16.

78. Mehta HB, Patel PK, Dixit BC, Dixit RB. Synthesis and antimicrobial activities of new mono and bisphenyl linked bispyrazole and bispyrazolone derivatives. Arabian J Chem 2017;10:S1901-12.

79. Prabhudeva MG, Prabhuswamy M, Kumar AD, Lokanath NK, Naveen S, Kumar KA. Synthesis, crystal and molecular structure and antimicrobial studies of 1-(3-chlorophenyl)-3-(5-chlorothiophen-2-yl)5-phenyl-4, 5-dihydro-1H-pyrazole. Chem Data Collect 2017;9:80-8.

80. Rangaswamy J, Kumar HV, Harini ST, Naik N. Functionalized 3-(benzofuran-2-yl)-5-(4-methoxyphenyl)-4, 5-dihydro-1H-pyrazole scaffolds: A new class of antimicrobials and antioxidants. Arabian J Chem 2017;10:S2685-696. 